\title{
Designing Motivation System to Produce Creativity and Entrepreneurship in Petrochemical Company
}

\author{
Aryan Gholipour \\ Associate Professor, Public Administration Department, University of Tehran \\ Tehran, Iran \\ E-mail: agholipor@ut.ac.ir \\ Ali Pirannejad \\ Ph.D Candidate in Organizational Behavior, University of Tehran \\ Tehran, Iran \\ Samira Fakheri Kozekanan \\ Ph.D Candidate in Organizational Behavior, University of Tehran \\ Tehran, Iran \\ Fattaneh Gholipour \\ Master in Financial Management, Islamic Azad University \\ Tehran, Iran
}

Received: August 23, $2010 \quad$ Accepted: January 17, $2011 \quad$ doi:10.5539/ijbm.v6n5p137

This research has been accomplished by the support of university of Tehran. Here we gratefully acknowledge the research vice president and public administration department for bestowing the grant to this research.

\begin{abstract}
Motivation is the essence of creativity and innovation and it is like fuel for them and makes them continue. Therefore this paper is identifying the motivating factors in Petrochemical Company. To produce innovation and expand technology, based on Sathe model, four series of mechanisms are considered: internal, non-financial, direct financial and indirect financial mechanisms. In addition, based on this model industrial and institutional stimuli are regarded the cause of innovation. The research sample includes managers and experts of the company and the data has been collected through interview and questionnaire. The results of the research reveal that the strongest motivations for innovation are the internal ones.
\end{abstract}

Keywords: Motivation, Creativity, Innovation

\section{Introduction}

In the changeable and complicated present life, companies need innovation and innovative approaches to organizational issues so that they can survive, expand and develop as well as gaining the power to compete and becoming perfect. Studies show that supporting innovation and creativity in an organization or in other words adapting strategies to support encouraging innovative factors has many benefits, such as increasing the possibility of attracting new investment, booming the research and development part, offering new products and services, earning business competitive advantage and earning legitimacy from the society (Lanjouw, 2005).

Contrary to the idea of the majority who believe that in past decades, innovation and creating job opportunities have been mostly done by personal entrepreneurship, it has been done by big companies. Creating job 
opportunities needs an intelligent and active leader who faces the changes of the market and products cleverly and be able to mange different human relationships (Drucker, 2003). Therefore innovators and entrepreneurs who are inside the organization are of vital importance to company, oil industry and the society of Iran and the managers should pay attention to it in particular. Innovation in oil industry confirms what peter Drucker has said and can change Iran greatly. In this context the conditions of creating ideas, products and new process inside the organization becomes important. There are several factors involved but in this paper we work on designing proper motivating systems to produce innovation and expand technology. Creating double motivation in innovators is very important because it is necessary for reviving oil industry and creating new ideas and products. For creating innovation and expanding technology in petrochemical research company, based on Sathe model there are two classes of factors: Pushing Factors and Pulling Factors.

\section{Industry motives in creating innovation}

Customers demand is one of the main pressures for creating innovation and expanding technology (Sathe, 2003, 41). These demands make the process of production and new process continuous. Of course we have to be careful because satisfied customers may slow down the process of development. In addition to satisfied customers, the innovation of the suppliers will also cause pressures for expanding the technology. Higher capability of the suppliers means more pressure to improve innovation and expand technology (Sathe, 2003, 44) in addition the level of competitiveness in industry and the threat of alternative products are some of the motivating factors in innovation in the company. Dick Fately the production manager of AMP sigcom believes that completion in industry is efficient in expanding new products. "If we cannot expand a new product, we cannot become stable and will collapse. If we do not do this, someone else will do it" (Sathe, 2003, 45)

Contacting customers, rivals and other external factors to gain information, ideas and support will create a big network of foreign interaction. The vastness of this interaction and contract network varies from one department to another. Every department which has a vaster interaction provides a better ground for innovation. (Sathe, 2003, 168)

Defining and guarantying patent, Governmental laws and regulations, industrial standards, consultants who are out of the company and new technology are also important in empowering and developing innovation and should be of great importance to the managers. Lack of industrial standards leads in customers' uncertainty (Sathe, 52-41:2003) regarding the mentioned pressures the first pre assumption will be:

\section{P1: industrial factors are forces to produce innovation and develop technology.}

\section{Organizational Stimulus for producing innovation}

Organizational factors are among the influential factors in producing innovation and developing technology. Managers' expectations from employees to create ideas, new products and new process can intensify the process of innovation. Managers' expectations of increasing productivity, reducing costs and improving customer services, can prepare the ground for employees' innovation. Low expectations can lead in loss of innovation. In fact what occurs here is Pygmalion and Golem effect. Pygmalion Effect, or Self -fulfilling prophecy says that people's beliefs and expectations determine their behavior and performance. People's real performance is the realization of their expectations (Manzoni and Barsoux, 1998) therefore the negative side of Pygmalion Effect or the Set - up to - fail syndrome has to be avoided. This is called Golem Effect which is poor performance due to low expectations of the managers (Davidson and Eden, 2000, McNatt and Judge,2004) .the experience of Microsoft Company has proved the success of institutionalizing this Effect. In Microsoft Company previous projects have accomplished in due time (Hamm and Port, 1999).

Another innovation Stimulus is gaining results which are very important to the company. Creating values for the company make the employees feel proud. In long term, employees will gain lots of benefits because of innovation. Their career path depends on innovation and gets them promoted (Sathe, 2003, 169).

Organization policies about dismissal or punishment of the employees who are not innovative can also be a pressure in developing the process of innovation. Certainly, you have to be very cautious about it. Department managers try to encourage employees to create new ideas in order to avoid punishment. You have to emphasize on creating new products and process but at the same time you have to keep the spirits of the employees high (Satheh, 169:2003). Regarding the three mentioned factor the second pre assumption will be as followed:

\section{P2: organizational factors are effective pressure forces for production innovation and developing technology.}

It is interesting to know that all the studies and researches that had been carried out on innovation in the organizations so far, unanimously point that environmental factors play an important role (Christiansen, 1977, 
Aldrich, 2000). In other words they dealt with the issue of creating jobs and innovation, looking in from outside and inter-organization attitude had no role in these studies. Fortunately recently these issues has been studies from motivating and encouraging mechanisms point of view inside the organizations and has finally focused on these studies from s new point of view and is preparing for huge changes in motivating systems and even the strategy of the organizations (Aldrich and Zimmer, 1986, Carroll and Mosakowski, 1987).

The studies that have a critical approach to the issue of motivation in organizations believe that the biggest defect of these theories is ignoring encouraging and improving of entrepreneurs. They claim that common people who have low-level demands and needs are the subject of the present motivating theories and the minorities who are the entrepreneurs and creative people have been ignored (Aldrich and Zimmer, 1986, 32). Regarding the indicated defect, this weakness has become more noticeable because the organizations are looking for competitive benefits and beating their rivals and therefore they have to offer preferable products and services or a high-quality product to gain popularity in society. This need leads the organizations to adapt motivating mechanisms for the minority (entrepreneurs, innovators and creative members) in their motivating systems.

As you can see in the above diagram, to improve some mechanisms to enrich job creating, motivating variants have been studies from two points of views: the need to ambitiousness: the researches which has been done on the characteristics of ambitious people, especially McClelland and Johnson( a review on 23 studies on this subject) shows that there is a positive and meaningful connection between being ambitious and being innovative and entrepreneur (McClelland 1961, Johnson, 1990) organizational entrepreneur s are very risk-taking. For example you can see that most entrepreneur $\mathrm{s}$ are after making a new business which is surely very risky in compare with working in a company (McClelland, 1961, Begley, 1995, Venkataraman, 1997). Entrepreneurs can stand ambiguity more than common people (Miller and Drodge, 1986). Entrepreneurs have inner control center and believe that they have control over their affairs and activities (McClelland, 1961, Begley, 1995, Rotter, 1966). Self- respect can be seen in organizational efforts, products and services and can earn competitive benefits for the organization (Bandora, 1997). Entrepreneurs and innovative people are highly self-reliant and this exact feeling leads them to accept the responsibility of what they do (Aldrich, 1977). We have to remember that creative people, like every other people, in the organizations need some motivators to create new ideas (Locke and Latham, 1990). Briefly saying, we can divide innovation encouraging mechanisms in an organization as followed: 1- patent 2-gross sales benefit 3- Subsidy for research and development4- reward for inventions5- research and development by governmental institutions 6- contract research and development (Lanjo, 2005). After carrying out polling, some obstacles were mentioned in the way of flourishing innovation and supporting it (Mclane, 2005; Troy, 2004; Jaruzelski et al, 2005) including: insufficient sources, lack of any formal strategy for innovation, lack of clear goals, insufficient support from leaders and ,managers, tendency towards short term attitudes and lack on any instruction for innovation. The existence of all these obstacles kills innovation and the opportunity to develop technology.

We have be aware that based on Effect Rule, innovation, like every other factors, must be encouraged to survive or there has to be a stimulus to lead people to innovation and creativity. Creative people and entrepreneur 's behavior is under the control of its consequences. This behavior happens automatically rather than a reaction. But after it happened, the repetition of this behavior depends on the quality of its consequence. When there is no good prize for innovation, it is not very likely that it happens again. The process of forming a creative behavior is controlled by four mechanisms: Positive reinforcement, Negative reinforcement, Punishment, Extinction. These for methods are identified based on the type of stimulus (negative/ annoying, positive/pleasing) and existence of the stimulus (adding or removing the stimulus). In addition to the four mentioned mechanisms, we can use David Premack principle to form the innovative behavior. Also, the consequence of behavior (and even its degree) is influential in future behaviors time of occurrence is important in this matter (Ferster and Skinner, 1957). Time is of importance so that a specific consequence can be related to a specific behavior. Time schedule, determines the pattern of supporting creative behaviors of the employees in an organization.

\section{Personal stimulus of producing innovation}

The personnel's stimulus for innovation can be internal or external (Sathe, 2003, 300). Internal motivations and rewards are valuable for the person by themselves; it means doing the job is the reward the person demands. The reward is an inseparable part of the job itself. In this case, the person goes towards the goal automatically. Internal rewards include feeling competent, feeling free and independent, feeling satisfied and tranquil.

Unlike internal rewards that the person is the source, external rewards come from outside. It means that doing the job by itself is not a reward for the person. The most common external rewards are the financial ones, like salary, wages, bonuses, cash prizes, coupons and etc. Of course external rewards doesn't simply limit to money or financial supports. Appreciating and admiring the employee, promotion, a bigger office with a nicer 
decoration, a private secretary can also come in this category. Getting external rewards doesn't depend on the person only, but other factors are involved as well. It means giving reward depends on the policies of the organization and it costs a fortune for the organization. Cash pays provides the person with a better welfare. The non-cash rewards are those that don't change a person's life financially but their working and living environment becomes more pleasant.

In some cases people have strong motives because they want to prove something to themselves or other people (Sathe, 2003). Internal motives are so stronger than external ones that they call the effect on internal motives on innovation" the principal of internal motive innovation" (Amabile, 1977). People are most innovative when they are motivated by the attraction of the job or when it is challenging, satisfying and entertaining by itself. Generally saying, internal motivation, not external ones like various external pressures including salary and wages, position, medals and promotions, wining prizes, pleasing the others, avoiding punishment, doing someone's command, gaining satisfactory evaluation. One of the characteristics of an innovative company is rewarding the innovators. But they avoid external motivations like money to tempt the innovative employees (Amabile, 1998). Because financial reward makes them feel under control. On the other hand not rewarding innovation can cause negative feeling in organization because the person may feel that he has been abused or unappreciated, and hardly ever it is possible to make someone motivated while he feels unappreciated. Therefore, there have been some suggestions as internal motivation and consequently increasing innovation: letting people work on their favorite project, thanking and appreciating their creative work generously and letting them work on their own favorite ideas even there is no assurance about the success of that project, but the system pays for this permission and it influences innovation. For instance, 3M Company allocates some time to its employees to spend on their own inventions. It can not only teach the employees to develop their ideas and learn from their mistakes, but also can be beneficial for the company. Internal motivations such as growing independence, more opportunities for professional and personal growth support innovation.

People who haven't been promised a reward (external), show more innovation than those who have been (Kruglanski et al., 1977). On the other hand, studies show that external rewards can encourage innovation for instance, the job which was done by people who were promised a reward was remarkably more innovative than the job which was done by those who weren't. Based on Vroom expectation theory, a person is motivated to perform better, when he understands that his efforts has led into some results and these result will bring him a good reward. Therefore in financial reward is important to a person, these kinds of rewards can motivate their innovation. But the primary focus of expectation theory is on external rewards and internal ones have been renounced. Certainly, it is possible that the relation between financial rewards and innovation is influenced by other variants. For example in Iran, income and consumption are important, so financial rewards bring security, freedom and self confidence along. Therefore, external rewards can have positive effect on internal ones and innovation. Therefore the first hypothesis can be:

\section{H1: internal motivations have a significant, positive effect on innovation and development of technology in petrochemical company.}

If one does a job that is interesting for him (internal motivation) and then receives external reward (external motivation) for it, how would be his motivations for doing that job? Although normally it is thought that in the mentioned situation both motivations, external and internal, come together and add to the power of the motivation of the named person, some researchers (like Amabil, 1998, and Desi and his colleagues (1999) believe it is not always so, because some external motivations leaves a negative effect on the internal source of some behaviors and reflects it in the outside world and decreases the freedom and independence of the person, therefore it will end in a weakened motivation and consequently in reduced innovation. This weakened motivation which is caused by external motivations is called" potential harms of external rewards". Although external rewards may sometimes weaken the internal motivations, the external rewards can be the sign of regarding a person important and appreciating his personal abilities. Since changing the internal motivation is very difficult, these innate defects, usually justifies the external motivations (Lee and Ahn, 2006, 940). There has been interesting studies about potential harms of external rewards. In one of these studies they classified people in three groups: expecting rewards (if you draw well you will get a letter of honor), without rewards (draw if you like) unexpected reward (draw if you like). As you can see, drawing in the first group is based on external motivations and in the second two groups it is based on internal motivation. After they finished drawing, the first group received their rewards and the second group also got an unexpected reward for the good painting. One week later, the researches offered the chance to the groups to draw as they wished. The result showed that the expecting reward group spends less time for drawing in compare with the other two groups and also the quality of their work was lower, because their internal motivation and interest was weakened by external reward, while it didn't happen to the other two groups. 
The interest of the expecting reward group is of special importance, because it makes it clear that the tendency towards external motivation, not the reward by itself, was the main reason of reduced interest among the students. In the other words it was not the reward that made them less interested, but it was the relation between the job and the thing that was supposed to be gained that reduced self-motivation and shifted the source on motivation from internal to external. On the other hand if the external rewards are random and unexpected, they empower the internal motivation and innovation.

Among the majority, cognizance is a strong motivation for innovation. Gibson, a Xerox Company manager, says that he is satisfied with his job and he would like to be known as a person who has changed the world like Henry Ford and Tom Watson (the legendary manager of IBM). He says that he doesn't want a silver or bronze medal and works hard for the gold (Sathe, 2003, 171). There is an important question: how should be the external financial motivations for innovative people and entrepreneurs? Should they be treated like independent entrepreneurs that get a lot of financial stimulus to compensate the risks they have taken? Basically it is supposed that if the risk is low or the spent time is not a lot, there is no need to financial stimulus. Of course, we have to keep in mind that there are some differences between independent entrepreneurs and organizational entrepreneurs. Independent entrepreneurs have big motivations like being the first, a pioneer or a founder in their own field, which also has big financial benefits for them. Organizational entrepreneurs don't enjoy these motivations, because they use the sources of the organizations and they haven't gained them therefore it is the organization that will be the founder not them (Sathe, 2003, 63).

Seeing this issue from Adams's" Equity theory" point of view is of importance. High payments to the innovators and entrepreneurs of the company will cause misunderstanding in the company. The experience in Xerox Company shows that when the innovators get really big rewards, they become millionaires and leave the Xerox. The consequence of this type of motivating system is that the innovators will soon leave the organization and will be considered like thieves who have stolen a fortune from the company in the eyes of the other employees. This also effects the cooperation inside a department negatively and will destroy the motivation in that department and consequently in the other departments. What should be done then? Should we forget about high motivating rewards? High financial rewards can be given in two cases: the people who receive these motivating rewards must be independent and detached from the organization their success or failure should be solely based on their own efforts and cooperation and they shouldn't receive any help from the organization. If these two conditions are provided, we can enjoy the benefits of high financial rewards in innovation and development of technology and avoid its negative consequences at the same time.

3M managers strongly believe that non-financial motivations like appreciating, recognition and respect, job promotion, elevating the social status and providing opportunities for participating in innovative projects in a larger scale will provide strong motivations for innovation and developing technology. These motivations and internal motivations will provide ideal condition for innovation and developing technology (Sathe, 2003, 63).

Mike walker, one of the managers of AMP, says: "people ask us what kind of incentives we have to empower innovation and productivity in our company". We answer: "appreciation, there is no cash pay". 3M managers also believe that there is no need to financial motivation for innovation. Buddy March, one of the managers, says: there is no financial reward for original ideas in marketing department, sales department and production department. All the members of different departments, like a family, become happy to hear about innovations and inventions. We have come up with an honor letter that all innovative employees would love to get it (Sathe, 2003, 66).

Some researchers believe that external rewards can be applied with two different goals: controlling and informative. If we apply them with controlling purpose, Amanil is right that external rewards can control people's behavior and finally ends in less internal motivation and innovation, but if they are used with informative goals, it means that the rewards have some information that reflects the competence and performance of the innovators in can lead to an increase in internal motivation and innovation. None of the rewards are harmful by themselves for innovation but there are two important factors that mustn't be ignored: what types of behavior should be rewarded and how should the rewards be distributed. For instance, they say that rewards can be used to transfer important information to the employees and these are the exact information that will effect internal motivation and finally innovation. Therefore rewards should be considered as signs of employees' qualifications and effort and their commitment to innovation, and then they will influence them positively. To understand the informative and controlling role of the rewards think of a manger who wants to reward his employee. Controlling, he would say: you've done your job well. You have done it exactly as we expected". Informative: he would say: "you have done your job, well. Your production ability has increased 10\%". As you can see the controlling reward includes pressure, frame work and it controls while the informative one expressed the person's skills and abilities and that he deserves to be rewarded. 
Now the main question pops: if there is no financial reward, will the employees take the risk of innovation and work to develop technology. Employees will take risks to be creative while there are no financial rewards and the chance of failure only if there is no personal risk (Levinthal and March, 1993). Managers should change the concept of risk in the mid of employees and be their bodyguards and protect them from risk (Sathe, 2003, 30). Do not forget that no personal risk doesn't mean job security necessarily. When employees only have job security, they won't be innovative, they have to be sure that there is failure and mistakes are taken well. It is very important to cultivate a culture and an atmosphere which can tolerate mistakes and failures. (Amabil, 1998), cultivating a culture that instead of reprimanding mistakes, encourages learning from them.

A downside of this culture that may happen is loss of responsibility on the side of employees when they see that the company takes all the responsibility of the failures. It is a phenomenon that economists call it" Moral Hazard". This is the basic assumption of this phenomenon is that if the employees won't accept responsibility if they are sure there is no control or punishment. This assumption is mentioned in X theory of McGregor (1960). One way to deal with this phenomenon is tolerating bad luck and punishment, in the other words if the employees made a bad decision, they have to be punished, but still there is a better way: to employ committed geniuses who intend to stay long with the organization and if they go on the right path of promotion, they will accept the responsibility of their own decisions in long term. If the person can not succeed because of too many opportunities, the right solution is to transfer him to another department so that he can work well. This will encourage the spirit of innovation in the company. When employees pursuit new unusual ideas, they should be supported by the managers (Sathe, 203:2002).

One of the stimuli to employees' innovation in an organization, is giving them the right to pursuit their personal commercial ideas, in the other words they should have the right to follow their commercial ideas. Both $3 \mathrm{M}$ and Amp managers believe that people need to follow their commercial ideas and even they can challenge the culture and policies of the company. The employees are free to do anything if it is legal, moral and beneficial. A stimulus to innovation in a company is being flexible in rules and laws and banning forbidden behaviors. Adherence to bureaucratic regulations will strangle innovation. To produce innovation and develop technology, regulations are just signs to guide the behaviors. If irresponsible behaviors are clearly mentioned, it is a great help to innovation and creativity because freedom in doing a job is a motivating factor (Sathe, 2002, 205).

Regarding what has been mentioned so far, the second, third and forth hypothesis will be as followed:

H2: External, non-financial incentives have a significant positive effect on innovation and development of technology in Petrochemical company.

H3: External, non-financial, indirect incentives have a significant positive effect on innovation and development of technology in Petrochemical research and technology Company.

H4: External, financial, direct incentives have a significant positive effect on innovation and development of technology in Petrochemical research and technology Company.

The time of rewarding is an important factor in motivating innovation. Researches show that when the time of rewarding is not fixed, it has a stronger effect on innovation and when the times are fixed and predictable they are less effective (Burchett and Willoughby, 2004, 529).

The system of non-constant rewarding and its sequence is of great importance to innovation (Saari and Latham, 1982). Rewarding can be monthly like salary but the motivation caused by this type of rewarding won't be as good as the one which is based on performance. Rewarding based on a changeable time pattern motivates the person more than the regular ones. To encourage the innovator, predictable and regular payoff -centered shouldn't be used (Kanter, 1983) because the employees will dislike using salary as a fixed reward for the innovator (Jain and Triandis, 1990). They believe that there is no connection between the monthly salary and the performance and innovation in research fields. For an alternative they suggest irregular and unpredictable payments based on performance to motivate the employees. Some researches support this idea. For instance, in one study, 33 high-tech, innovative companies and 72companies with lower technology and less innovative were under study and they found out that sharing the profit was more popular in the high-tech companies. Regarding all these discussions, it becomes clear that just salary cannot provide the required motivation, but financial payments like having a share in profit which is a feedback of the employees' performance can influence innovation among researchers and scholars.

Performance-based rewarding is efficient. Emphasizing the role of organizational rewarding process on people's behavior, they believe that the likelihood of innovation and innovation will increase when people feel that the rewards are fair and based on performance or skills. Also a fair, performance-based rewarding system is influential 
on innovation. When a rewarding is based on performance and its informative aspect is stronger than its controlling aspect, it can increase internal motivation and subsequently more innovation (Abbey and Dickson, 1983). Therefore the fifth hypothesis of the research will be:

\section{H5: unpredictable, non-constant incentives have more effect on innovation developing technology in petrochemical research and technology Company.}

It has been believed that someone will win as long as his competitor loses while both can be winners, because people's interests and abilities can come together and become stronger. In the other words if the employees cooperate with each other and the management also cooperated with them, both will enjoy better conditions (Parkinson and colleagues, 1987). Based on this idea if the rewards makes the employees compete with each other it will have a negative on innovation. When the employees feel that they are being evaluated in compare with the others and only the best will be rewarded, they become less innovative. For instance Amabil (1997) studied the effects of competing on innovation on two groups. The first group was told to paint and then 3 people would get a reward by lottery. The second group was told that 3 of the best paintings would be rewarded. Arad and his colleagues (1997) indicate in their researches that the behaviors which are rewarded show the values of an organization. If innovative behaviors are rewarded, they become dominant. But here is the problem in most organizations, the managers expect their employees to be more innovative and risk taking, while they always reward the old, tested behaviors which is not very possible to fail. To encourage employees to be innovative they should be rewarded for taking risks, experiencing, production and performing their new ideas in their jobs.

The rewards should be properly flexible to match individual needs (Thomson, 1983). The role of liberty in rewarding has been studied. The results show that people prefer to be punished by choice but they are not willing to get a reward without their own decision. The importance of reward and punishment changes dramatically when it comes to the matter of choice. In self service method, instead of a collection of fixed rewards, the organization provides the employees with a various collection of rewards and let them to choose freely up to a set limit. This make the employee more satisfied and facilitates recruiting new employees (Shafritz and Ott, 1995). In Intellectual property rights system, to protect copyright, the patent is an important motivating factor. Intellectual property rights have no clear advantage over rewarding system. Surely, if a person can combine Intellectual property rights system with a rewarding system, a better outcome can be expected. Nowadays in any field registering Intellectual property rights is influential on innovation and therefore on financial motivations, what is clear is that the rewards are used less (Shavell and Ypersele, 1998).

\section{Methodology}

In this research, Triangulation method has been used. There are various types of Triangulation; in the present research we have used the Multiple Triangulation. Multiple Triangulations consists of Triangulation of the data which has been collected from different sources like questionnaires and interviews. Investigator Triangulation has been used also. In this method three investigator are used so that the weakness of one will be covered by the strength of the other. In addition Method Triangulation has also been used; it means both quality and quantity have been taken into account. It has been tried to look at motivation mechanisms through Entrepreneurship theory and motivation theories. Thus Triangulation theories also have been used. The following variants have been regarded as dependant variants: internal incentives, non-financial external incentives, indirect financial external incentives and direct financial incentives. The statistical sample includes team mangers, petrochemical research and technology development company experts. The sample has been taken randomly.

To collect data for this research, questionnaires and interviews have been used. The questions have been designed so that they are simple and clear. The first questionnaire had 100 questions that 13 of them were deleted to factor load. the questionnaire is based on Likert scale as 5- strongly agree, 4-agree, 3- neither agree nor disagree, 3 -disagree, 1- strongly disagree. Cronbach's Alpha Coefficient of incentive with 33 questions was $86 \%$ and for innovation with 54 questions it is $89 \%$.

Validity is checked by both content validity and factor validity. Content validity is evaluated through professors and experts. Factor validity test of inquiry is performed by confirmatory factor analysis using LISREL 8.53 software. One of the most common methods of collecting data is interview. Interview with open questions let the interviewee to explain their experience about the subject completely. It is the ideal method for sharing information. To meet the comfort of the interviewees, the time had been arranged before with their own consent.

The interviews which had been structured to some extent were deep. It means the questions were neither predefined nor completely free. There had been a general overview of the topic and the discussion had been around five fix questions. During the interview notes were taken to have a record of the information, though it was easier 
to use tape recorders but due to high conservative culture of the country they were never used. Since the interviewees were a beneficiary party in this issue and they were sensitive about it, it was very interesting for them.

Though there was no limitation in questions but the interviewer tried to keep the track around the following questions. Which non-financial mechanisms can encourage the employees of the factory to be innovative and try to develop the technology? What are the direct financial mechanisms for producing innovation? What indirect non-financial mechanisms can be used in petrochemical research and technology Company? Does it make any difference if the incentives are fixe cot non-constant? How far can the internal motivations be effective in innovation?

As you can see the questions are general and comprehensive so that the interview can be under control by asking about the details. We have tried to make the questions simple and understandable so that the interviewees can answer them based on their own information. The interview started with simple questions and moved up to the more difficult ones. Before starting the interviews we had a meeting with the chief of technology and policy making of the company and made sure that the questions were proper. To analyze the relation between the variants, we used Spearman rank correlation test with SPSS 15 software, and Structural equation modeling method for reviewing the cause and effect relationship between independent and dependant variants of the research by using LISREL 8.53 software. Due to limitation in number of pages models and tables have been omitted.

\section{Discussion and Conclusion}

The results show that the main incentive for the researchers is respect and their dignity and position. In departments they try to provide a respectful atmosphere among the employees which by itself is a positive factor in motivating the members to have appositive feeling towards their job. The researcher feels that their work place is an appreciating one, and it makes them feel satisfied inside. Since most of the activities in the company are mental, most of the incentives are internal. To encourage the researches more and gain their trust, their activities and ideas are presented in different meetings, seminars, etc with their own name. it is widely seen that despite insufficient financial sources, the researches work up until late at nights on their projects while there is no noticeable difference about the external incentives between those who work till the end of official working time and those who work overtime to finishing the project which they are interested in, they earn more or less the same. And this is a confirmation that internal incentives are really important for researchers.

In the departments most of the researchers are university elites (18+ average and from creditable universities). We have to notice that they are the academic and scientific type and the way they are treated should be different from other usual employees, because they are doing mental jobs while the others are doing physical jobs. And that is exactly the reason that makes the issue very sensitive and doubles the responsibility of the managers and in charge authorities.

Another thing which had been done in this company to support innovation is making the responsibilities specific and clear and they are not abstract and it makes the responsibilities clear and answering is easier. Clarity has influence on creativity. Another encouraging factor for the researchers is the method of managing the company that doesn't depend on an individual and the managers do not trust only in themselves and leave some of their responsibilities with their employees, in most cases the employees perform the job better and thus the trust becomes stronger on both sides. Doing so the managers train their employees because they are aware that if they don't do so, they won't progress and this will harm them, because if there is nobody to replace the present manager he doesn't have the chance to get a promotion himself. One of the internal incentives that motivates the researches' innovation and makes them work harder in Oil and petrochemical Company is the high position of this company in the society and this position and dignity makes them to behave beyond their responsibility and role. Another incentive that makes the researches do beyond their responsibility is the brand of oil Company. As you know oil company has a high position in our country and researcher feel good about working for our company and work overtime. What are important to the researcher is his Intellectual property rights. Because a researcher is a sensitive person and he should feel safe, because in unsecure situations, new ideas won't flourish. In other words, potential talents won't become actual. Although internal incentives are important for researchers, if a person has problem with providing facilities for his family and had financial problems, his mind will be busy and there won't be any chance for innovation.

Another obstacle in the way of creativity and innovation is the vagueness of the goals and major strategies of research institutions and companies in our country which makes it impossible to direct the activities towards a desirable future. Also most of the high rank managers of the government are operational managers and are not familiar with research and research works and the related problems and obstacles. Another factor that can flourish innovation in an organization is flexibility and not limiting the researchers with formalities and 
regulations, because these limitations are a hindrance to innovation. And to prevent any possible abuse we have to just set the frame work and let the researchers work freely inside this framework.

\section{Resources}

Aldrich, H., \& Zimmer, C. (1986). Entrepreneurs through social networks. In D. L. Sexton \& R. W. Smilor (Eds.), The art and science of entrepreneurship (pp.3-23). Cambridge, MA: Ballinger.

Begley, T. M. (1995). Using founder status, age of firm, and company growth rate as the basis for distinguishing entrepreneurs form managers of smaller businesses. Journal of Business Venturing, 10, 249-263.

Carroll, G., and Mosakowski, E. (1987). The career dynamics of self-employment. Administrative Science Quarterly, 32, pp. 570-589.

Christiansen, Calyton M. (1997). The Innovator's Dilemma: When New Technologies Cause Great Firms to Fail. Boston: Harvard Business School Press.

Collins, M. D., Lawson, P. A., Nikolaitchouk, N., \& Falsen, E. (2000). Luteococcus peritonei sp. nov., isolated from the human peritoneum. Int J Syst Evol Microbiol, 50, 179-181.

Davidson, O. B \& Eden, D. (2000). Remedial self-fulfilling prophecy: Two field experiments to prevent Golem effects among disadvantaged women. Journal of Applied Psychology, 85, 386-398.

Johnson, B.R. (1990). Toward a multidimensional model of entrepreneurship: the case of achievement motivation and the entrepreneur. Entrepreneurship Theory and Practice, Spring, pp. 39-54.

Lanjouw, J.O. (2005). Patens, Price Controls and Access to New Drugs: How Policy Affects Global Market Entry. Manzoni, J.-F., and J.-L. Barsoux. (1998). The Set-Up-To-Fail Syndrome. Harvard Business Review, 101-113.

McClelland, D.C. (1961). The achieving society. Princeton: Van Nostrand.

McNatt, D. B., \& Judge, T. A. (2004). Boundary conditions of the galatea effect: A field experiment and constructive replication. The Academy of Management Journal, 47, 550-565.

Miller, D., \& Drodge, C. (1986). Psychological and traditional determinants of structure. Administrative Science Quarterly, 31, 539-560.

Sathe, Vijay. (2003). Corporate Entrepreneurship: Top Managers and New Business Creation. Cambridge, U.K.: Cambridge University Press.

Sexton, D.L., \& Bowman, N.B. (1986). Validation of a personality index: comparative psychological characteristics analysis of female entrepreneurs, managers, entrepreneurship students, and business students. Frontiers of entrepreneurship research (pp. 513-528). Wellesley, MA: Babson College.

Venkataraman, S. (1997). The distinctive domain of entrepreneurship research: an editor's perspective. In J. Katz, \& R. Brockhaus (Eds.), Advances in entrepreneurship, firm emergence, and growth, vol. 3 (pp. 119-138). Greenwich, CT: JAI Press. 